\title{
Mitochondrial dysfunction-mediated apoptosis resistance associates with defective heat shock protein response in African-American men with prostate cancer
}

\author{
Ajay K Chaudhary ${ }^{1,5}$, Tariq A Bhat ${ }^{1,5}$, Sandeep Kumar ${ }^{1}$, Anil Kumar ${ }^{2}$, Rahul Kumar ${ }^{1}$, Willie Underwood ${ }^{3}$, \\ Shahriar Koochekpour ${ }^{3,4}$, Mojgan Shourideh ${ }^{4}$, Neelu Yadav ${ }^{1}$, Shanta Dhar ${ }^{2}$ and Dhyan Chandra*,1 \\ ${ }^{1}$ Department of Pharmacology and Therapeutics, Roswell Park Cancer Institute, Elm and Carlton Streets, Buffalo, NY 14263, USA; \\ ${ }^{2}$ NanoTherapeutics Research Laboratory, Department of Chemistry, University of Georgia, Athens, GA 30602, USA; ${ }^{3}$ Department \\ of Urology, Roswell Park Cancer Institute, Buffalo, NY 14263, USA and ${ }^{4}$ Department of Cancer Genetics, Roswell Park Cancer \\ Institute, Buffalo, NY 14263, USA
}

Background: African-American (AA) patients with prostate cancer ( $\mathrm{PCa}$ ) respond poorly to current therapy compared with Caucasian American (CA) PCa patients. Although underlying mechanisms are not defined, mitochondrial dysfunction is a key reason for this disparity.

Methods: Cell death, cell cycle, and mitochondrial function/stress were analysed by flow cytometry or by Seahorse XF24 analyzer. Expression of cellular proteins was determined using immunoblotting and real-time PCR analyses. Cell survival/motility was evaluated by clonogenic, cell migration, and gelatin zymography assays.

Results: Glycolytic pathway inhibitor dichloroacetate (DCA) inhibited cell proliferation in both AA PCa cells (AA cells) and CA PCa cells (CA cells). AA cells possess reduced endogenous reactive oxygen species, mitochondrial membrane potential (mtMP), and mitochondrial mass compared with CA cells. DCA upregulated mtMP in both cell types, whereas mitochondrial mass was significantly increased in CA cells. DCA enhanced taxol-induced cell death in CA cells while sensitising AA cells to doxorubicin. Reduced expression of heat shock proteins (HSPs) was observed in AA cells, whereas DCA induced expression of CHOP, C/EBP, HSP60, and HSP90 in CA cells. AA cells are more aggressive and metastatic than CA cells.

Conclusions: Restoration of mitochondrial function may provide new option for reducing PCa health disparity among American men.

It is well documented that prostate cancer $(\mathrm{PCa})$ health disparities exist between African-American (AA) and Caucasian American (CA) men regarding the diagnoses, mortalities, disease aggressiveness, response to therapies, and prognosis (Godley et al, 2003; Chornokur et al, 2011). Indeed, incidence of PCa in AA men is $\sim 1.5$ times higher and mortality rates $2-3$ times more than CA men (McIntosh, 1997). Furthermore, AA men poorly respond to conventional PCa treatment modalities, often show higher tumour relapse and a low 5-year disease-free survival (Powell et al, 1997, 2000; Grossfeld et al, 2002; Godley et al, 2003; Latini et al, 2006; Chornokur et al, 2011). Although reasons behind this disparity are largely unknown and multifactorial; family history, dietary habits,

\footnotetext{
*Correspondence: Dr D Chandra; E-mail: dhyan.chandra@roswellpark.org

${ }^{5}$ These authors contributed equally to this work.
}

Revised 10 March 2016; accepted 10 March 2016; published online 26 April 2016

(c) 2016 Cancer Research UK. All rights reserved 0007-0920/16 
socioeconomic conditions, and genetic factors contribute to such outcomes (Underwood et al, 2004; Chornokur et al, 2011; Hayn et al, 2011). Indeed, AA patients with PCa harbour reduced level of mitochondrial DNA (mtDNA) (Koochekpour et al, 2013), suggesting that reduced mitochondrial function in AA cells might be one of the key reasons for resistance to apoptosis in AA cells and apparent PCa health disparity. Mutations, reduction, or deletion of mtDNA are linked to many physiological anomalies including defective oxidative phosphorylation (OXPHOS) activity, deregulated reactive oxygen species (ROS) production, and hyperactive glycolytic pathway (Warburg effect). Disturbance of these mitochondrial parameters have been linked to carcinogenesis, promotion, and progression of the disease (Alirol and Martinou, 2006; Chatterjee et al, 2006; Majmundar et al, 2010; $\mathrm{Yu}, 2012)$. Mitochondrial dysfunction also confers resistance against various conventional anticancer regimens in tumours (Pelicano et al, 2006; Chen et al, 2010; Indran et al, 2011).

Mitochondrial apoptotic pathway requires cytochrome $c$ release from mitochondrial with subsequent formation of apoptosome causing execution of caspase-dependent apoptosis (Green and Reed, 1998). Normal OXPHOS activity, steady state ROS, and mitochondrial membrane potential (mtMP) are critical determinants of apoptosis induction via mitochondrial pathway (Dey and Moraes, 2000; Simon et al, 2000). OXPHOS is largely defective and glycolytic pathway is normally employed for ATP production in cancer cells, which associates with tumour cell proliferation, survival, invasion, and metastasis (Warburg, 1956; Pecqueur et al, 2013; Zhao et al, 2013). Metabolic targeting of key enzymes regulating balance between mitochondrial glucose oxidation and cytoplasmic glycolysis including pyruvate dehydrogenase kinase (PDK), lactate dehydrogenase, and pyruvate kinase has shown to induce apoptosis, decrease cell proliferation, and tumour growth (Michelakis et al, 2008; Pecqueur et al, 2013; Zhao et al, 2013). Restoration of mitochondrial activity in cancer cells induces tumour cell death and halts tumour growth (Bonnet et al, 2007). Dichloroacetate (DCA), a small molecule and inhibitor of PDK, thus activates pyruvate dehydrogenase, causing decreased tumour growth in many cancers (Fantin et al, 2006; Bonnet et al, 2007; Pecqueur et al, 2013). Therefore, cell death induction in cancer cells by reviving mitochondrial activity could be an important strategy for cancer prevention and treatment. In the present study, we investigated the underlying mechanism of cellular proliferation, cell death, cellular invasion and metastasis in both AA and CA cells on restoring mitochondrial function by DCA.

\section{MATERIALS AND METHODS}

Cells and reagents. CA LNCaP, Du145, and PC3 cells were obtained from ATCC, while E006AA and E006AA-hT, AA prostate cancer cell lines were established and characterised by Dr Koochekpour's laboratory (Koochekpour et al, 2004, 2014). Cells were maintained as recommended by ATCC. Primary antibodies against HSP10 and cell cycle and apoptotic cocktail (pCdk/pHH3/Actin/PARP), anti-MMP-9, anti-MMP-2 were from Abcam, MA, USA; anti-HSP60 was from Chemicon; anti-HSP90 from R\&D Systems USA, anti-HSP70 from Stressgen, USA; and anti-actin antibody was from M.P. Biomedical USA. Rabbit and mouse HRP-labelled secondary antibodies were procured from GE Healthcare Life Sciences, Pittsburgh, PA, USA. All other reagents were purchased from Sigma-Aldrich, St. Louis, MO, USA.

Measurements of mitochondrial ROS, cellular ROS, mtMP, and mitochondrial mass using flow cytometer. PCa cells were treated or left untreated with DCA for indicated doses and times described in figure legends. Mitochondrial ROS, cellular ROS, mtMP, and mitochondrial mass were measured using MitoSox
Red, DHR123, MitoTracker Orange, and MitoTracker Green, respectively, according to our recently published articles (Yadav et al, 2015, 2016).

Whole-cell lysate preparation and caspase activities, cytosol and mitochondrial purification, and western blotting. PCa cells were treated with various agents as described in figure legends. Whole-cell lysate, cytosol, and mitochondrial fractions were prepared. Equal amounts of protein were subjected to caspase activities or western blotting as described previously (Srivastava et al, 2012).

Cell migration assay. PCa cells were seeded in a 6-well culture dishes and grown to confluence. Using sterile $200 \mu$ l micropipette tip, two parallel scratches were created in each well. The floating cells were removed immediately after creating scratches followed by addition of fresh medium containing mitomycin $\mathrm{C}\left(5 \mu \mathrm{g} \mathrm{ml}^{-1}\right)$ and indicated doses of DCA. Wound closure was recorded by photography at 0 and $15 \mathrm{~h}$ after scratch using an inverted microscope (Olympus IX73) equipped with digital camera. The wound closure by PCa cell migration was observed and measured after $15 \mathrm{~h}$ of treatment, and data are represented as per cent cell migration compared with control.

Clonogenic survival assays. PCa cells at a density of 500 cells per well in a 6-well tissue culture dishes were cultured followed by treatment with the indicated doses of DCA for 7 days. Cells were washed, fixed with chilled $95 \%$ ethanol for $10 \mathrm{~min}$, and stained with crystal violet solution $(0.05 \%$ in distilled water) for $30 \mathrm{~min}$ at room temperature followed by colony counting using phase contrast microscope.

Gelatin zymography. Cells were seeded and grown to $70 \%$ confluence in $60 \mathrm{~mm}$ dishes followed by overnight serum starvation, and subsequently, cells were treated with DCA at $20 \mathrm{mM}$ dose under serum-starved conditions for $48 \mathrm{~h}$. After the treatment, media were collected and gelatin zymography was performed as per manufacturer instructions (Novex 10\% Zymogram Gel, Life Technologies, NY, USA).

Cell surface marker profiling. Cells were treated with DCA followed by staining with stem cell markers CD44 (FITC-tagged) and/or CD133 (APC-tagged) for $15 \mathrm{~min}$ at $4{ }^{\circ} \mathrm{C}$ in dark. Cells were centrifuged at 1500 r.p.m. at $4{ }^{\circ} \mathrm{C}$ for $5 \mathrm{~min}$ and resuspended in $500 \mu \mathrm{l}$ of $1 \mathrm{X}$ PBS, and analysed using flow cytometer. At least Five hundred thousand events were collected for each sample.

Cell growth, cell death, and cell cycle analysis. PCa cells were treated with different drugs alone or in combinations for indicated time points. Percentage cell death was quantified using Trypan blue method or Annexin V/PI methods (Yadav et al, 2016). For cell cycle analysis, PCa cells were treated with DCA for indicated doses and times. Cells were fixed with $70 \%$ ice-cold ethanol for $1 \mathrm{~h}$ at $4{ }^{\circ} \mathrm{C}$, washed with PBS and stained with PI in the presence of $0.02 \mu \mathrm{g} / \mathrm{ml}$ RNase A. Finally, samples were analysed using BD LSR II flow cytometer and Modfit analysis as described previously (Srivastava et al, 2012).

Real-time PCR analysis. For real-time PCR analysis, cDNA prepared from control and $24 \mathrm{~h}$ DCA treated PCa cells were used to quantitate the expression of protein involved in UPR including $\mathrm{C} / \mathrm{EBP}$ homologous protein (CHOP), CCAAT/enhancer binding protein (C/EBP), chaperone DnaJ (DnaJ), HSP10, HSP27, HSP60, HSP70, and HSP90 using the primer pairs listed in Supplementary Table S1.

Seahorse XF24 bioenergetics mitostress assay. Different parameters associated with mitochondrial respiration such as basal respiration, coupling efficiency, and spare respiratory capacity in PC3 prostate cancer cell line were assessed by MitoStress assay by using a Seahorse XF24 (Seahorse Biosciences, 
North Billerica, MA, USA) analyzer as described previously (Pathak et al, 2014).

Statistical analysis. Results are presented as mean \pm s.d. of data from at least three independent experiments. Statistical analyses were performed using GraphPad Prism and significance was calculated using one-way ANOVA (San Diego, CA, USA).

\section{RESULTS}

DCA suppresses growth and induces cell death in CA cells compared with AA cells. To address whether restoration of OXPHOS could be an effective strategy to treat AA patients with $\mathrm{PCa}$, we treated E006AA cells derived from AA PCa patient (Koochekpour et al, 2004) with DCA. We also used highly
A

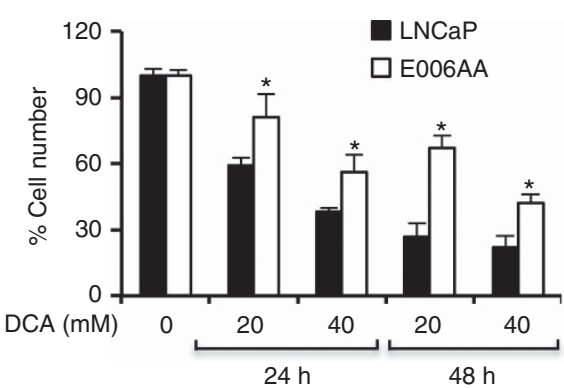

D

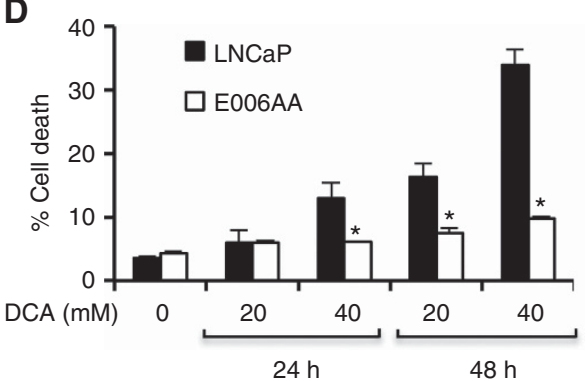

B
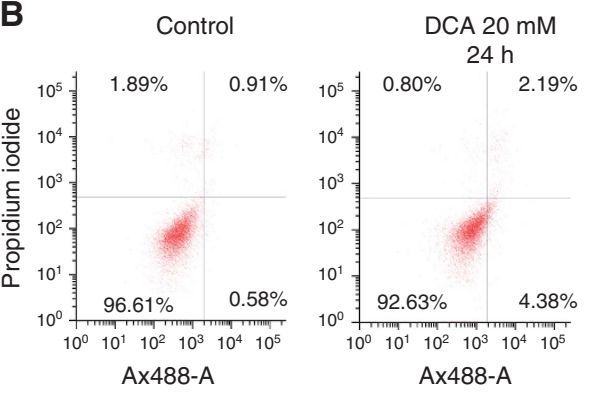

C

Control

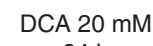
$24 \mathrm{~h}$

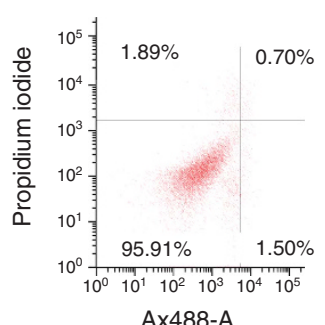

Ax488-A

E

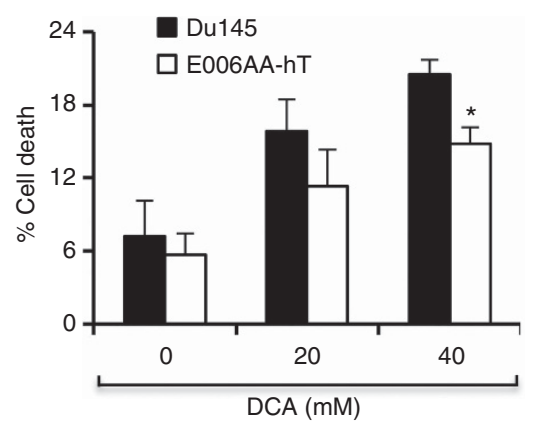

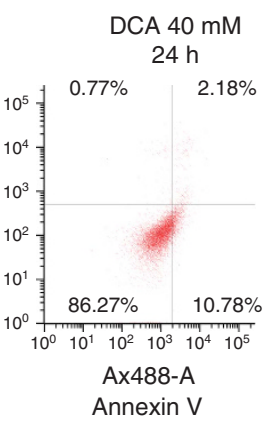
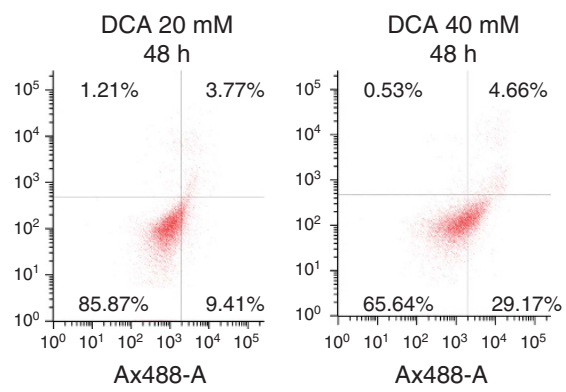

Annexin V

DCA $40 \mathrm{mM}$ $24 \mathrm{~h}$
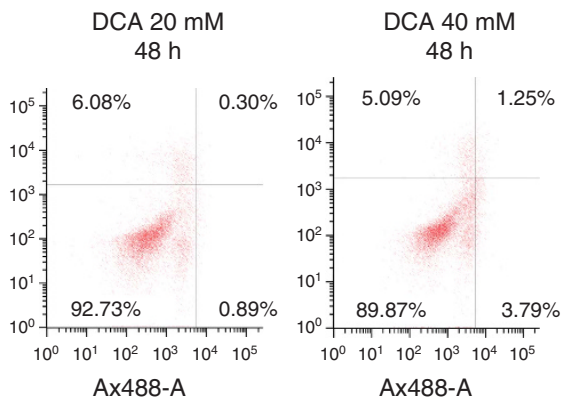

Annexin V

F

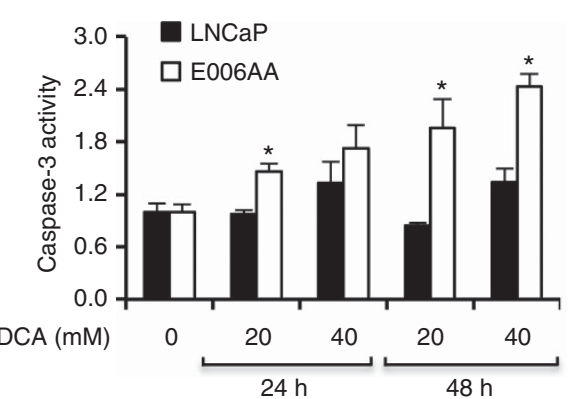

Figure 1. DCA inhibits CA cell proliferation compared with AA cells. (A) Cells were treated with dichloroacetate (DCA) at indicated doses/time and live cells were counted using trypan blue method. (B and C) LNCaP and E006AA PCa cells were treated with DCA at indicated doses for 24 h time intervals followed by Annexin V/PI labelling, and total cell death (D) was quantified by flow cytometry analysis. (E) Du145 and E006AA-hT cells were treated with DCA at indicated doses for $24 \mathrm{~h}$ and cell death was quantified using trypan blue staining. (F) Cells were treated with DCA at indicated doses for $24 \mathrm{~h}$. DEVDase (caspase-3) activity was measured using equal amounts of whole-cell lysates. Data are mean \pm s.d., $n=3$,

$\star P \leqslant 0.05$ compared with respective LNCaP or Du145 cells. 
tumourigenic E006AA-hT cells derived from parental E006AA cells (Koochekpour et al, 2014). For CA cells, we treated androgendependent LNCaP and androgen-independent Du145 cells with different doses of DCA. We observed that DCA strongly suppresses cell proliferation of LNCaP and Du145 while only slight reduction of cell proliferation in E006AA and highly tumourigenic E006AA-hT cells (Figure 1A, and data not shown). DCA induced significant cell death in CA compared with AA PCa cells (Figure 1B-E). DCA has ability to restore OXPHOS, which activates caspases (Bonnet et al, 2007; Cao et al, 2008). Indeed, we observed that DCA treatment activates caspase-3 at higher level in AA cells compared with CA cells (Figure 1F). Thus cell death induction in AA cells by DCA is, in part, mediated by caspase activation, while in CA cells caspase activation may not be a sole reason for cell death induction by DCA.

DCA fails to reduce cancer stem cells (CSCs) population in AA cells compared with CA cells. CSCs offer resistance to current
A
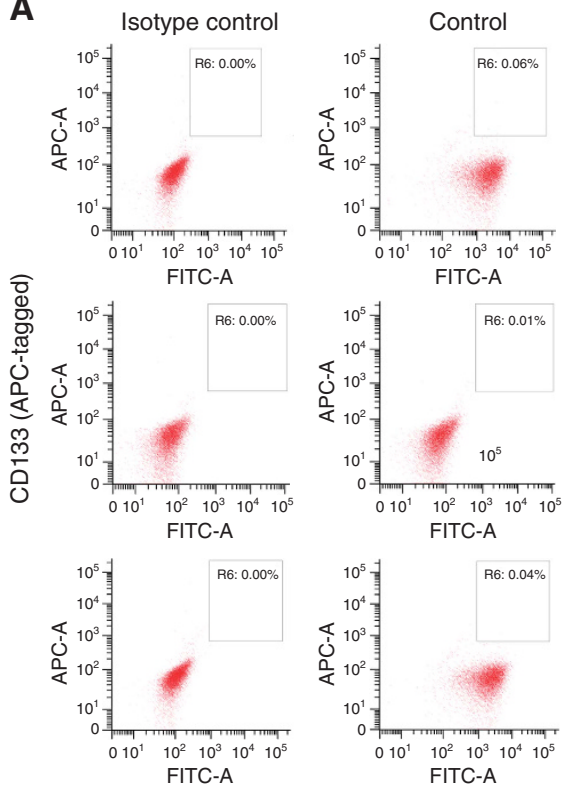
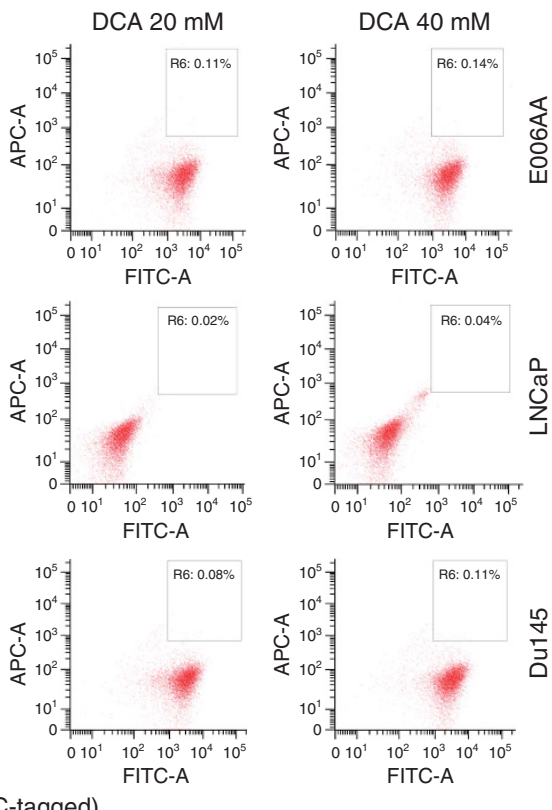

\section{B}

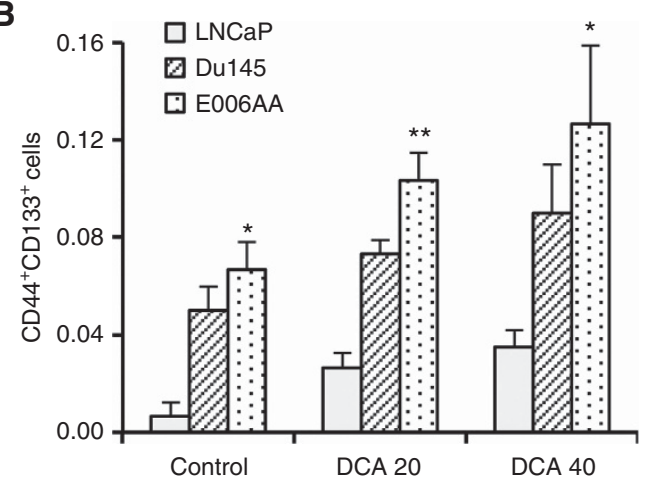

D

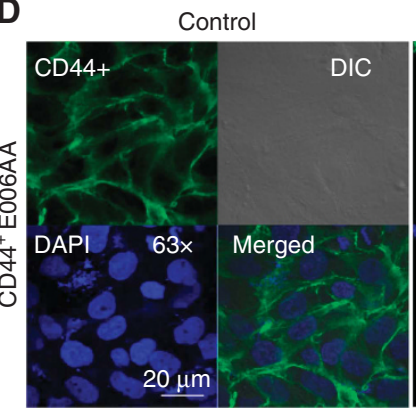

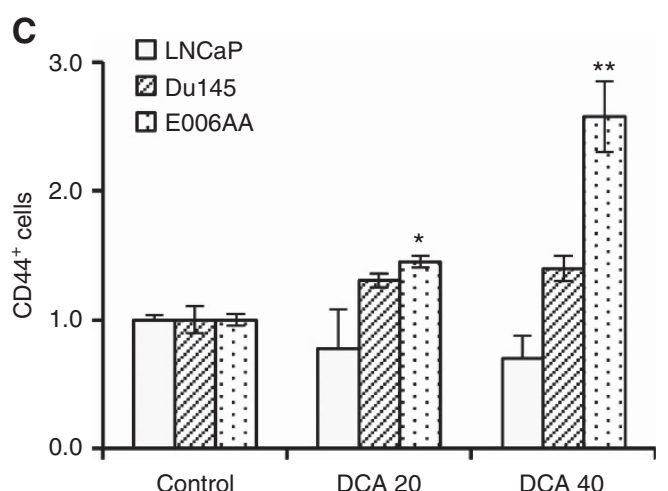

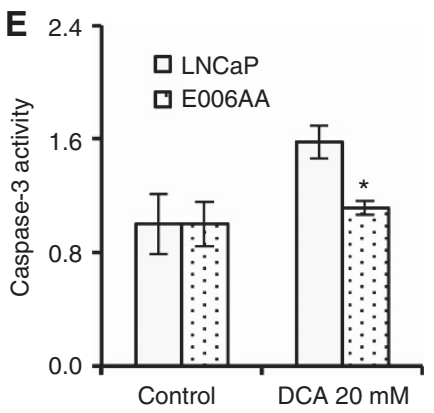

Figure 2. AA cells show increased enrichment of CSCs on DCA treatment. (A-C) Cells were treated with DCA at indicated doses for $24 \mathrm{~h}$. Cells were harvested and stained with indicated PCa stem cell markers and processed for flow cytometry analysis. (D) E006AA cells were plated on coverslips and treated with DCA ( $40 \mathrm{mM})$ for $24 \mathrm{~h}$ and immunolabelled with CD44 antibody linked with AlexaFluor 488 and image were captured using Zeiss LSM710 confocal microscope. (E) Cells were plated on low attachment dishes to generate CSC spheres followed by treatment with DCA. After 3 days DCA treatment, DEVDase (caspase-3) activity was measured using equal amounts of proteins from control and treated spheres. Data are mean \pm s.d., $n=3,{ }^{*} P \leqslant 0.05$ compared with respective LNCaP cells. ${ }^{* \star} P \leqslant 0.05$ compared with respective LNCaP and Du145 cells. 
therapies and have potential to regenerate tumours causing relapse in PCa (Collins et al, 2005). The CSCs profile in CA and AA cells on exposure to DCA demonstrated that E006AA cells harbour higher enrichment of $\mathrm{CD} 44^{+}$and $\mathrm{CD} 44^{+} \mathrm{CD} 133^{+}$populations in AA cells compared with CA cells, which did not decrease on DCA treatment (Figure 2A-D). Decreased number of spheres in CA compared with AA cells further provides evidence that DCA is more effective in CA CSCs (data not shown). Increased caspase activation in CA CSCs spheres compared with AA spheres on DCA treatment further support our conclusion that DCA has higher anticancer effect in CA CSCs (Figure 2E). This implies that CSCs in AA cells show relatively high resistance compared with CA counterparts towards anticancer agents.

Differential modulation of cell cycle phase distribution by DCA in AA and CA cells. Cell cycle arrest causes inhibition of cell proliferation and is accompanied by cell death (Evan et al, 1995; Pucci et al, 2000). Surprisingly, quantification of different stages of cell cycle demonstrated that DCA induced G1 and G2/M arrest in CA cells, whereas S-phase arrest was observed in AA cells

\section{A}

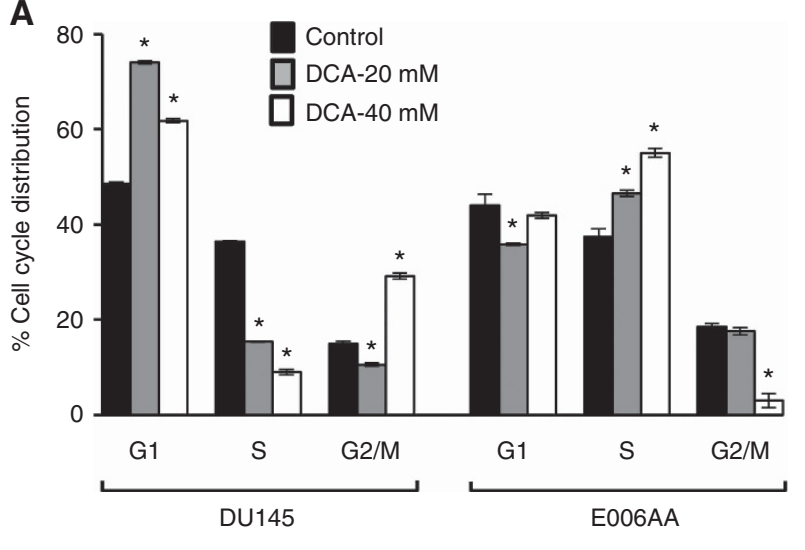

B
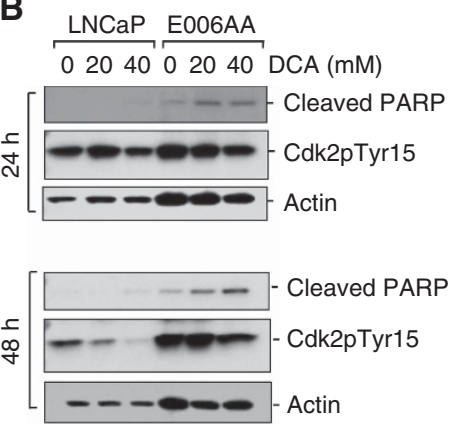

C
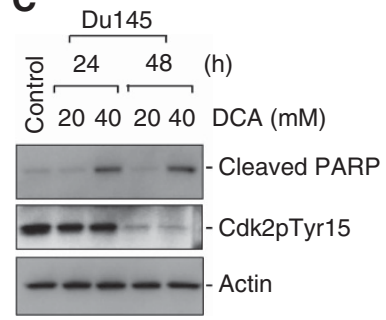

D

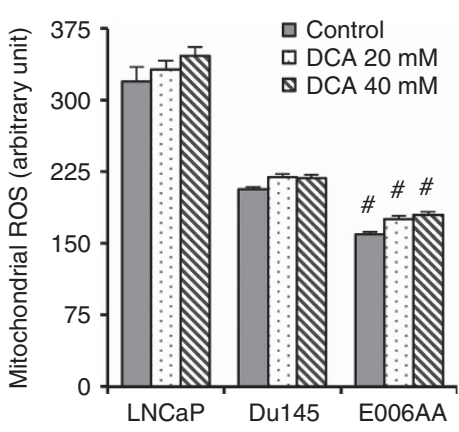

E

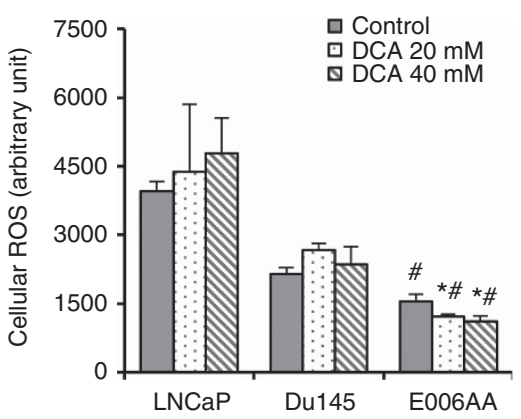

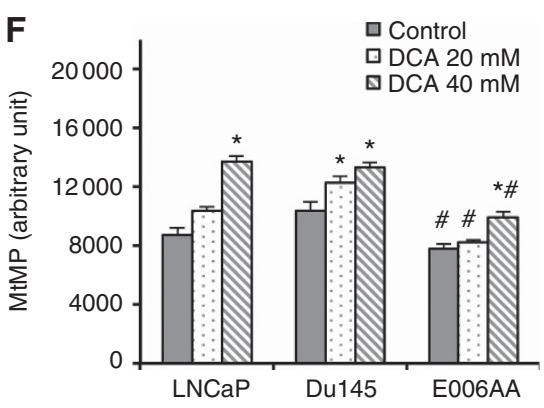

G

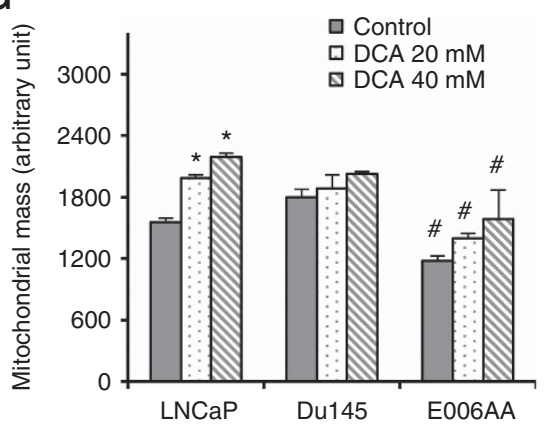

Figure 3. DCA induces differential cell cycle parameters and modulates mitochondrial functions. Cells were treated with DCA at indicated doses for $24 \mathrm{~h}$ followed by flow cytometry analysis to determine cell cycle phase distribution. Data are presented as the percentage of cell cycle distribution for each treatment group (A). Cells were treated with DCA at indicated doses for $24 \mathrm{~h}$. Equal amounts of protein was used for western blotting to determine the level of indicated proteins (B and $\mathbf{C}$ ). AA and CA cells were treated with DCA at indicated doses for $24 \mathrm{~h}$ time period. Cells were either stained live with MitoSox for mitochondrial ROS or MitoTracker Orange for mitochondrial membrane potential (mtMP), or dihydrorhodamine 123 (DHR123) for cellular ROS or MitoTracker Green for mitochondrial mass at $37^{\circ} \mathrm{C}$ (D-G). Cells were then analysed on flow cytometer. Data are mean \pm s.e., $n=3,{ }^{*} P \leqslant 0.05$ compared with respective controls. ${ }^{*} P \leqslant 0.05$ compared with LNCaP and Du145 control untreated cells. 
(Figure 3A). For example, compared with untreated Du145 cells with $\sim 49 \%$ cell population in G1 phase, DCA 20 and $40 \mathrm{mM}$ doses increased G1-phase cell population to $\sim 74$ and $\sim 62 \%$, respectively, after $24 \mathrm{~h}$. In addition, there were significantly reduced percentages of cells in S-phase of cell cycle at both 20 and $40 \mathrm{mM}$ of DCA treatment to Du145 cells (Figure 3A).

In E006AA cells, compared with $\sim 37.4 \%$ cell population in S-phase of control, DCA 20 and $40 \mathrm{mM}$ doses increased this cell population to $\sim 46.5$ and $\sim 55 \%$, respectively, after $24 \mathrm{~h}$ treatment (Figure 3A). It is interesting to note that increased accumulation of cells at S-phase were associated with decreased percentage of cells at $\mathrm{G} 1$ phase at $20 \mathrm{mM}$ and drastic reduction in $\mathrm{G} 2 / \mathrm{M}$ population with $40 \mathrm{mM}$ DCA treatment (Figure 3A). The elevated level of phosphorylated cyclin-dependent kinase $2(\mathrm{Cdk} 2)$ at Tyr15 (Cdk2 pTyr15) in E006AA cells on exposure to various doses of DCA suggests the loss of CDK2 activity leading to accumulation of cancer cells at S phase (Sebastian et al, 1993; Coulonval et al, 2003). Accumulation of cells at $S$ phase was corroborated with increased PARP cleavage supporting the notion that caspase activationmediated PARP cleavage in E006AA cells may associate with increased proliferation but not cell death (Figure $3 \mathrm{~B}$ and $\mathrm{C}$ ).

DCA differentially modulates mitochondrial functions in AA and CA cells. To determine whether DCA affect mitochondrial function, we examined the levels of mitochondrial ROS, cellular ROS, and mtMP in AA and CA cells. We observed that DCA increased mitochondrial ROS production albeit not significant both in AA cells and CA cells (Figure 3D). Surprisingly, we observed LNCaP and Du145 cells harbour significant high levels of endogenous level of mitochondrial and cellular ROS compared with E006AA cells. The DCA-induced mitochondrial ROS in AA cells was significantly lower compared with untreated CA cells (Figure 3D and E). Cellular ROS levels were decreased significantly in E006AA cells in response to DCA, but in LNCaP and Du145 cells, no significant changes were observed (Figure 3E).

We observed that DCA increased mtMP in LNCaP, Du145, and E006AA cells (Figure 3F). Like mitochondrial and cellular ROS, the levels of mtMP in E006AA cells were significantly lower than LNCaP cells (Figure $3 \mathrm{~F}$ ). We also observed reduced level of mitochondrial mass in AA cells compared with CA cells (Figure 3G). DCA induced mitochondrial mass significantly in LNCaP but not in Du145 and E006AA cells (Figure 3G). These findings suggest that AA cells possess strong mitochondrial dysfunction reflected as reduction in ROS production, mtMP, and mitochondrial mass.

AA cells possess defective heat shock protein (HSP) response compared with CA cells. Mitochondrial HSPs and proteases are known to be upregulated to protect dysfunctional mitochondria and its homeostasis (Haynes and Ron, 2010). This is mediated by mitochondrial unfolded protein response $\left(\mathrm{UPR}^{\mathrm{mt}}\right)$, a stress response reflecting mitochondrial state (Haynes and Ron, 2010; Altieri, 2011; Pellegrino et al, 2013). To understand whether AA and CA cells possess differential levels of protein folding machinery and $\mathrm{UPR}^{\mathrm{mt}}$, we evaluated transcriptional levels of key HSPs and UPR ${ }^{\mathrm{mt}}$ related proteins in LNCaP and E006AA cells, respectively. We observed reduced expression of transcription factor CHOP, whereas its dimerisation partner C/EBP was elevated in $\mathrm{LNCaP}$ cells compared with E006AA. Interestingly, UPR ${ }^{\mathrm{mt}}$ chaperone proteins $\mathrm{HSP} 60$ and DNAj were upregulated at transcriptional levels in LNCaP cells compared with E006AA cells (Figure 4A and B). Transcriptional levels of HSP70 and HSP90 were unchanged (Figure 4B). Western blot analysis further demonstrated increased expression of HSP10, HSP60, and HSP90 proteins in LNCaP cells (Figure 4C). Since HSP60 is a key protein for proper mitochondrial protein folding and $\mathrm{UPR}^{\mathrm{mt}}$ for restoration of mitochondrial function (Zhao et al, 2002), reduced level of HSP60 in AA cells may lead to defective cell death function of mitochondria in AA cells.

To understand the impact of protein folding machinery and HSPs on DCA-induced cell death in AA and CA cells, we detected the levels of key HSPs including protein folding proteins. We observed that DCA induced expression of HSP60, HSP90, and HSP27 but expression of HSP70 and HSP10 was unchanged in response to DCA treatment in $\mathrm{LNCaP}$ cells (Figure 4D). In E006AA cells, no changes were observed with HSP90, but transcription level of HSP27 and HSP10 mRNA were reduced, whereas HSP60 and HSP70 were upregulated transcriptionally in response to DCA treatment (Figure 4D). We observed increased expression of transcription factor for $\mathrm{UPR}^{\mathrm{mt}}$ including $\mathrm{CHOP}$ and its cofactor C/EBP (Aldridge et al, 2007) in response to DCA treatment in LNCaP cells. No changes were observed for CHOP and DNAj but C/EBP expression was reduced in E006AA cells (Figure 4E). Similar to LNCaP cells, transcriptional levels of protein folding and $\mathrm{UPR}^{\mathrm{mt}}$ proteins were upregulated in Du145 cells (Figure 4F). To understand whether HSPs play an important role in apoptosis, we treated LNCaP and E006AA cells with 17AAG (tanespimycin), an inhibitor of HSP90, in the presence and absence of DCA and measured caspase- 3 activity. We observed that 17-AAG enhanced DCA-induced caspase-3 activation in LNCaP cells, whereas it was inhibited in E006AA cells (Figure 4G).

AA cells are more aggressive and metastatic, and possess clonogenic survival advantage compared with CA cells. We next evaluated migration and clonogenic behaviour of two types of cells and observed that AA cells are highly migratory and possess high clonogenicity compared with CA cells. We observed that DCA showed 77 and $71 \%$ inhibition in cell migration in Du145 and PC3 cells, respectively. However, similar treatments suppressed this migratory potential in E006AA and E006AA-hT cells only by $\sim 30$ and $\sim 14 \%$, respectively (Figure $5 \mathrm{~A}$ and $\mathrm{B}$ ). We observed that DCA treatment blocked the clonogenic potential of CA cells and has less effect in AA cells (Figure 5C and D). We observed robust increased of both pro and active forms of MMP-9 and MMP-2 in E006AA cells but not in LNCaP cells (Figure 5E). Gelatin zymography demonstrated that AA cells have very high MMP-2 and MMP-9 activities compared with CA cells (Figure 5F). These results clearly indicate that AA cells have more metastatic potential than CA cells, which are critical for tumour progression and linked to mitochondrial dysfunction (Seliger et al, 2013).

DCA enhanced taxol-induced cell death in CA cells but not in AA cells. Advanced and metastatic PCa poorly responds to current therapies, and outcomes in AA patients with $\mathrm{PCa}$ are poorer compared with CA patients (Chornokur et al, 2011). We observed that DCA significantly sensitises CA cells to taxolinduced death while AA cells did not show enhanced cell death in the presence of DCA (Figure 6A-C). These observations emphasise that AA patients might get positive outcomes only after major restoration of mitochondrial function.

DCA enhances doxorubicin-induced cell death in AA cells and androgen-independent PC3 cells but not in androgen-dependent LNCaP cells. Interestingly, we observed that DCA enhanced doxorubicin (DNA damaging agent)-induced AA cell death (Figure 6D). Two different responses were observed with CA cells. Androgen-dependent LNCaP cells do not respond positively with doxorubicin in the presence of DCA, whereas androgen-independent PC3 cells show higher levels of cell death with doxorubicin and DCA combination (Figure 6D).

Effect of DCA and anticancer agents on mitochondrial bioenergetic functions in CA cells. To assess whether mitochondrial function was modulated in response to anticancer agents in CA cells, we measured oxygen consumption rates (OCRs) in PC3 cells as a way of assessing OXPHOS and hence ATP 

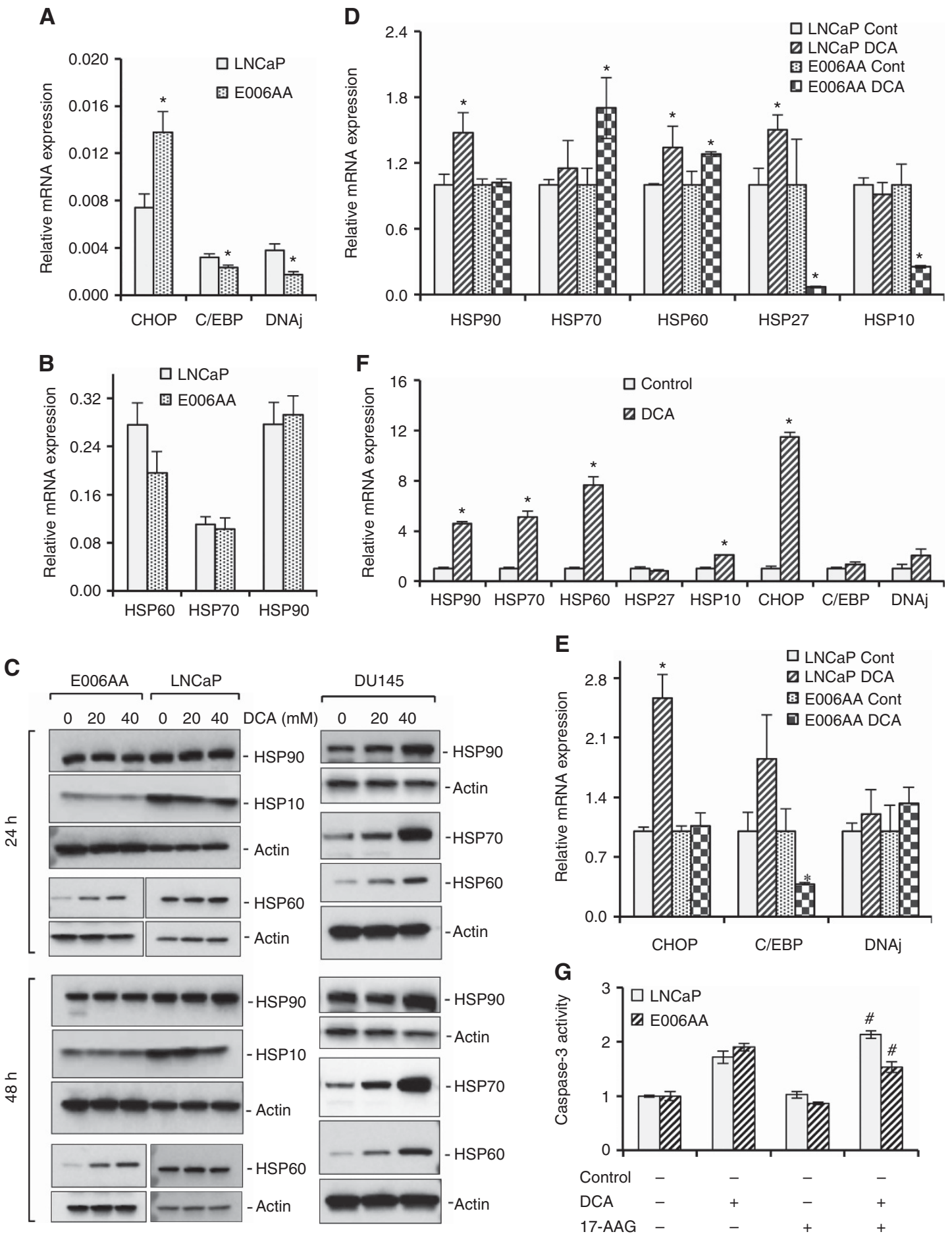

Figure 4. Existence of defective HSP response in AA cells but not in CA cells. Total RNA was isolated from AA (E006AA) and CA (LNCaP) cells and $1 \mu \mathrm{g}$ of total RNA was subjected to mRNA expression quantification for the indicated genes by RT-PCR analysis (A and B). Cells were treated with DCA at indicated doses and time periods. Whole-cell lysates were subjected to western blotting for the indicated proteins (C). Total RNA isolated from untreated or DCA (20 mM for $24 \mathrm{~h}$ ) treated LNCaP, Du145, and E006AA cells were subjected RT-PCR analysis for expression level of indicated HSPs and cofactors or activators (D-F). Cells were treated with 17-AAG (HSP90 inhibitor; $10 \mathrm{nM}$ for $24 \mathrm{~h}$ ) in the presence and absence of DCA $\left(40 \mathrm{mM}\right.$ for $24 \mathrm{~h}$ ) followed by caspase-3 activity measurements (G). Data are mean \pm s.d., $n=3,{ }^{\star} P \leqslant 0.05$ compared with respective controls. ${ }^{\#} P \leqslant 0.05$ compared with DCA treated cells.

production. Presence of oligomycin indicated that the levels of ATP-linked respiration were decreased in control cells or cells treated with DCA, paclitaxel (PTX), and DCA + PTX, whereas, doxorubicin (DOX) and DCA + DOX treatment did not show any significant changes. Subsequent addition of mitochondrial uncoupler p-triflouromethoxyphenylhydrazone (FCCP) indicated that except for DOX and DCA + DOX, all other treatment group showed an increase in the OCR levels similar to that of control treatment. Finally, injection of mitochondrial complex III inhibitor antimycin A together with mitochondrial complex I inhibitor rotenone significantly inhibited the OCR due to the collapse of ATP synthesis. When DCA was used in combination with DOX, a 
A

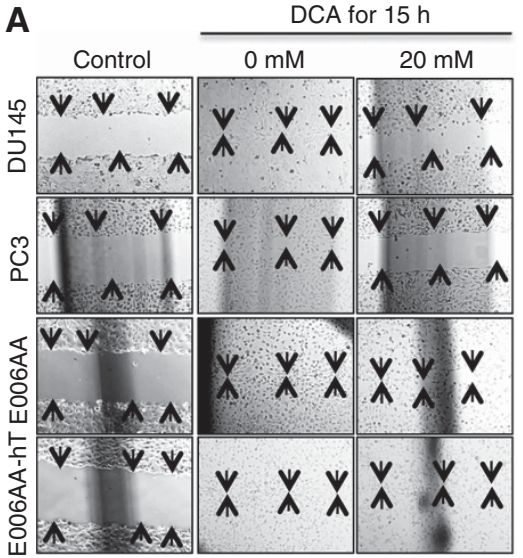

C (LNCaP)

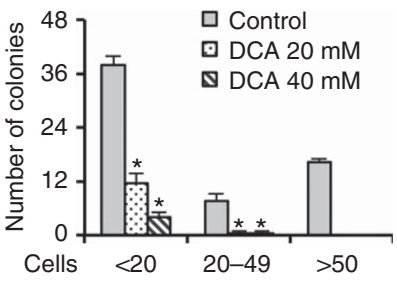

D (E006AA)

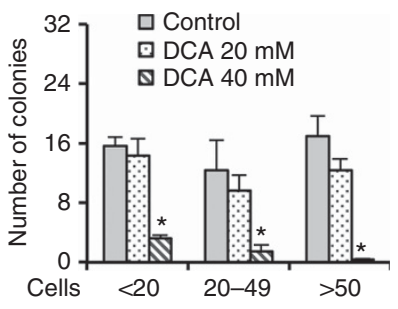

B

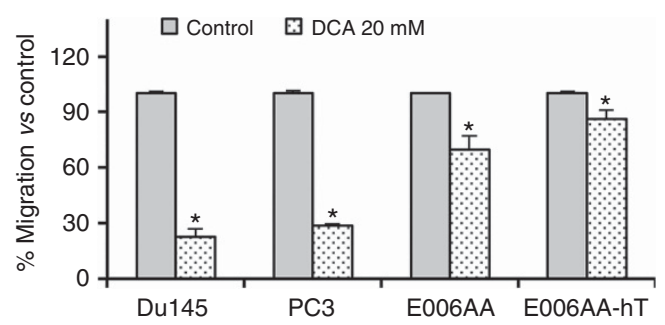

E
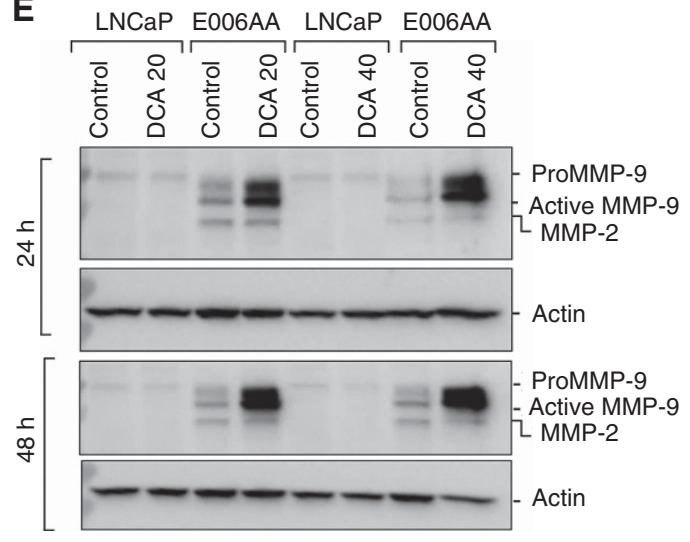

$\mathbf{F}$

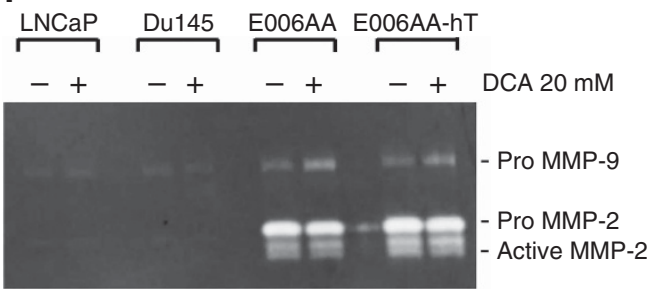

Figure 5. DCA strongly inhibits metastatic parameters including cell migration in CA cells, and AA cells possess strong MMP-2 and -9 activities. Cells were grown to confluence and wound was created with a sterile $200 \mu \mathrm{l}$ pipette tip. Wound healing under mitomycin $\mathrm{C}$ presence was continued in the absence or presence of DCA $(20 \mathrm{mM})$. Images $(\mathbf{A})$ were captured at 0 and $15 \mathrm{~h}$ time periods after treatment. Percentage cell migration (B) compared with control was calculated as discussed in Methods section. (C and D) Cells (500 cells per well) were cultured in a six-well dishes followed by treatment with the indicated doses of DCA for 7 days. Colonies of indicated sizes were counted using phase contrast microscope. PCa cells were cultured to $70 \%$ confluency; after overnight serum starvation, cells were treated with DCA at indicated doses for $48 \mathrm{~h}$. Equal amounts of protein were subjected to western blotting for indicated proteins and actin serves as loading control (E). An aliquot of media containing equal amount of proteins were separated on gelatin-containing zymogram gel. Zymogram gel was stained with Bio-Rad zymogram staining solution followed by destaining to get clear white MMP-gelatinolytic bands against the blue background (F). Data are mean \pm s.e., $n=3$, ${ }^{\star} P \leqslant 0.05$ compared with respective controls.

significant change in basal OCR levels was also observed as compared with the control cells. The cells treated with PTX and DCA, did not reflect any significant changes in the OCR as compared with the control treatment (Figure 6E and F; and data not shown). Further experiments are necessary to investigate the exact roles of these drugs related to mitochondrial bioenergetic functions.

\section{DISCUSSION}

Higher PCa incidence and mortality are commonly associated with AA men compared with CA men. AA patients with PCa respond poorly to same conventional therapies offered to CA PCa patients (Powell et al, 1997, 2000; Grossfeld et al, 2002; Godley et al, 2003; Chornokur et al, 2011). AA PCa patients are more likely to have early tumour relapse after primary treatment regimens compared with CA patients (Powell et al, 1997, 2000; Semenas et al, 2012). Mitochondrial dysfunction is a common defect in cancers and strongly linked to resistant to therapy causing tumour relapse owing to altered cellular physiology and defective cell death process (Alirol and Martinou, 2006; Chatterjee et al, 2006; Indran et al, 2011). Indeed, reduced mtDNA content associates with poor prognosis in AA patients compared with CA (Koochekpour et al, 2013). Optimal response to any conventional therapy requires functional death-inducing mitochondrial signalling, which in response to anticancer agents induce cancer cell death (Fischer and Schulze-Osthoff, 2005). Thus restoring steady state mitochondrial function will exert strong anticancer effects (Bonnet et al, 2007; Cao et al, 2008).

The present study highlights the importance of mitochondrial dysfunction in PCa health disparity. It is important to stress the severity of mitochondrial dysfunction in AA cells in the sense that a well known small-molecule DCA capable of promoting OXPHOS (Bonnet et al, 2007) could not restore mitochondrial function to the required threshold levels for apoptosis causing inefficient cell death in response to DCA or DCA in combination with taxol. Although a small increase in caspase activation was observed on 
A

Control
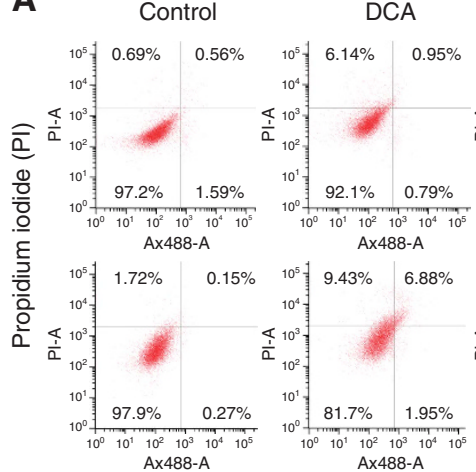

$10^{2} 10^{3}-10^{2}$
$\mathrm{Ax} 488-\mathrm{A}$

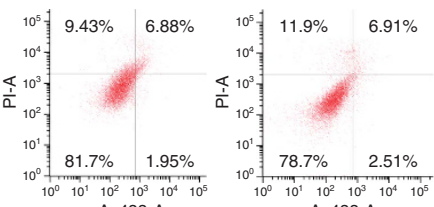

Annexin V

C

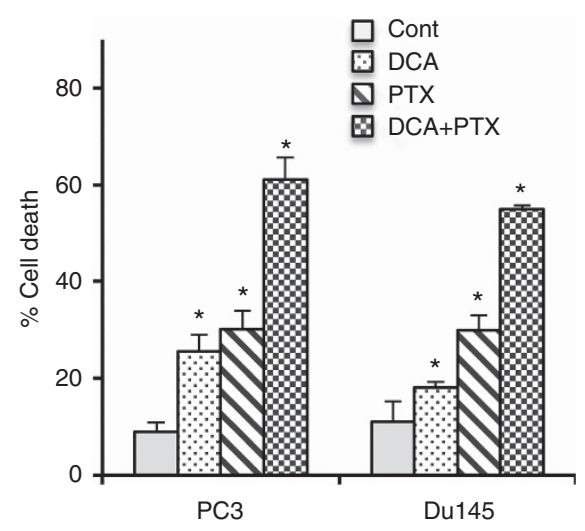

E

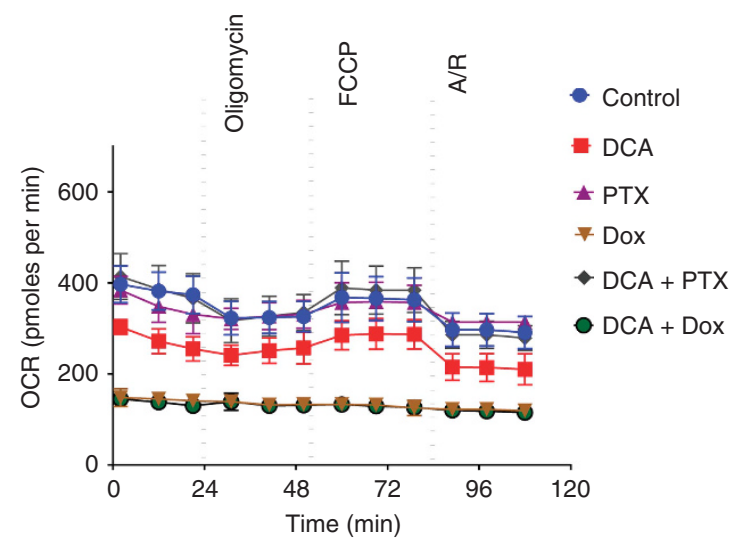

PTX+DCA
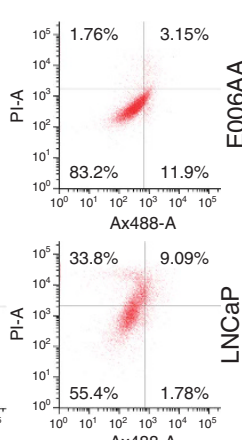

Ax488-A
A

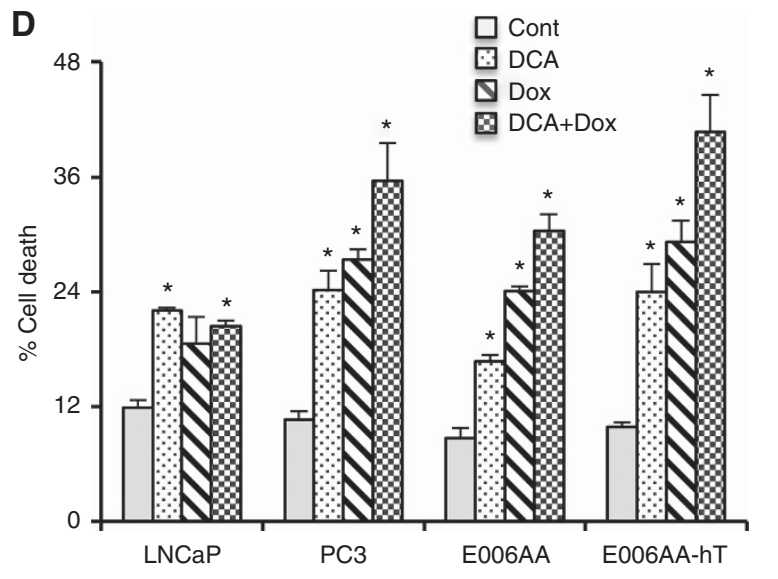

$\mathbf{F}$
B

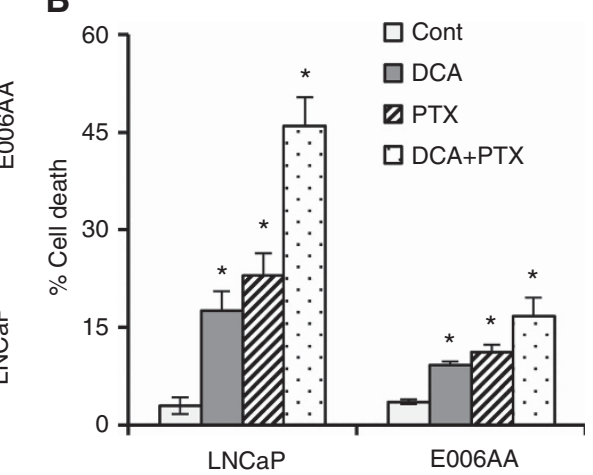

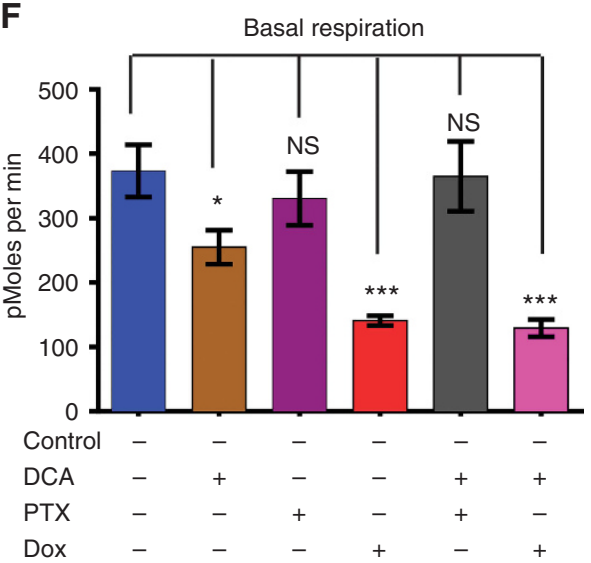

Figure 6. Taxol enhances CA cell sensitivity in the presence of DCA, whereas doxorubicin induces cancer cell sensitivity in both types of cells, and effect of DCA and anticancer agents on oxygen consumption rate (OCR). AA (E006AA) and CA (LNCaP, PC3, and Du145) cells were treated taxol $(30 \mathrm{nM})$ or doxorubicin $(100 \mathrm{nM})$ in the presence or absence of DCA $(20 \mathrm{mM})$ for $48 \mathrm{~h}$. At the end of the treatment time, percentage cell death was quantified either by annexin V labelling (A and B) or using Trypan blue staining method (C and D). PC3 cells were treated with 20 mM DCA alone or with indicated combinations of taxol (PTX, 30nM) or doxorubicin (Dox, $100 \mathrm{nM}$ ) for $24 \mathrm{~h}$. OCR traces were determined using a Seahorse mito stress kit and Seahorse XF24 analyzer (E). OCR before the addition of oligomycin and following the treatment of FCCP represent the basal mitochondrial respiration $(F)$ and maximal mitochondrial respiration capacity, respectively. OCR following rotenone plus antimycin $A$ treatment represents non-mitochondrial respiration. Data are mean \pm s.e., $n=3,{ }^{\star} P \leqslant 0.05$ compared with respective controls; ${ }^{\star \star} P \leqslant 0.01$ compared with respective controls.

DCA treatment, which may be associated with increased proliferation of AA PCa cells because a low level of caspase activation has been linked to tumour cell repopulation and tumourigenesis (Aldridge et al, 2007; Huang et al, 2011). Slight increase in caspase activation also associates with increase in both mitochondrial and cellular ROS, which could function as signalling molecules for cancer cell proliferation (Schieber and Chandel, 2014). Thus low levels of caspase activation accompanied by ROS production below threshold toxic levels could ultimately enhance
AA PCa cell proliferation. Indeed, these notions are supported by the fact that DCA fails to exert inhibitory effect on cell proliferation, invasion, and metastatic potential of AA PCa cells. In addition, DCA treatment also induced increased DNA synthesis in AA PCa cells during S-phase of cell cycle, whereas in CA PCa cells DNA synthesis was significantly reduced.

Taxol induces higher levels of cell death in the presence of DCA in CA PCa cells. Lack of caspase activation suggests that restoration of mitochondrial function may suppress the survival 
signalling causing increased cancer cell death without elevation of caspase activation. Inability of combined treatment of taxol and DCA to enhance ROS production and caspase activation further suggests the involvement of either caspase-independent cell death or non-apoptotic cell death in CA PCa cells (Tait et al, 2014). Restoration of mitochondrial function at normal steady state switches cancer cells from glycolytic state (pro-cancerous) to OXPHOS (anti-cancerous) state and may provide therapeutic advantage (Ponnala et al, 2012). However, AA cells possess very low basal levels of ROS and mtMP compared with CA cells, thus DCA induced increase in mitochondrial ROS and mtMP in AA cells may not be sufficient to induce apoptosis. Thus our findings suggest that mitochondrial dysfunction is an important factor responsible for resistance to conventional therapies in various cancers and AA subjects poorly respond to first line chemotherapy (Powell et al, 1997, 2000; Pelicano et al, 2006; Yu et al, 2007; Indran et al, 2011). We have recently shown that doxorubicin treatment induces mitochondrial biomass and function, which may lead to increased apoptotic cell death (Yadav et al, 2014). Indeed, doxorubicin-induced cell death in AA cells may be associated with restoration of some mitochondrial function to above threshold toxic levels. Since AA cells possess severely defective OXPHOS, doxorubicin-induced restoration of mitochondrial respiration is not sufficient to induce efficient AA cell death.

Cancer stem cell-like cells, a small subpopulation of cells, have been reported to be responsible for tumour progression, metastasis, drug resistance, and tumour relapse, and associate with poor response to conventional interventions (Collins et al, 2005). CSCs have also been isolated and characterised in case of $\mathrm{PCa}$ and are thought to be important for PCa development and metastatic progression (Collins et al, 2005). DCA treatment induces higher enrichment of $\mathrm{CD} 44^{+}$and $\mathrm{CD} 44^{+} \mathrm{CD} 133^{+}$cell populations in AA cells compared with CA cells, suggesting that CSCs from AA cells also harbour mitochondrial dysfunction, which could not be restored on DCA treatment. Since increased enrichment of CSCs associates with higher metastasis potential, mitochondrial dysfunction in CSCs may confer the higher metastatic features in AA cells compared with CA PCa cells.

$\mathrm{UPR}^{\mathrm{mt}}$ has been recognised as an important physiological process in regulating proper mitochondrial functioning and homeostasis, which regulate many processes including energy metabolism and apoptosis (Haynes and Ron, 2010; Haynes et al, 2010). Many players mediate $U_{P R}{ }^{\mathrm{mt}}$ including mitochondrial HSPs such as HSP60, HSP70, and HSP90 (Haynes and Ron, 2010; Haynes et al, 2010; Altieri, 2013). AA cells express lower level of HSP60 and HSP90 compared with CA cells. Since HSP60 plays a critical role in cancer cell survival and facilitates the function of various onco-proteins and mediates $\mathrm{UPR}^{\mathrm{mt}}$ to relieve stresses. This directly implies that AA PCa cells have strong mitochondrial dysfunctions, which may be mediated by HSP60 folding machinery and other prosurvival HSPs including HSP70 and HSP90. Together, we conclude that the presence of severe mitochondrial dysfunction in AA compared with CA PCa cells could be one of the potential reasons for the increased resistance, metastatic potential, and tumour recurrence in case of AA patients compared with CA counterpart in the clinic.

\section{ACKNOWLEDGEMENTS}

This work was supported in part by the National Cancer Institute of the National Institutes of Health under Award Number R01CA160685, the American Cancer Society Research Scholar Grant RSG-12-214-01 - CCG, and Department of Defense under Award Number W81XWH-14-1-0013 to DC; and the National Cancer Institute Center Support Grant P30 CA016056 to the
Roswell Park Cancer Institute. This work was also supported in part by the Department of Defense Prostate Cancer Idea award (W81XWH-12-1-0406) and the Office of the Vice President for Research, UGA, as a start-up fund to S.D. We thank Prof. Rick Tarleton for the Seahorse analyzer, and Alan J. Siegel for confocal images. We apologise to those colleagues whose publications could not be cited due to space constraints.

\section{CONFLICT OF INTEREST}

The authors declare no conflict of interest.

\section{REFERENCES}

Aldridge JE, Horibe T, Hoogenraad NJ (2007) Discovery of genes activated by the mitochondrial unfolded protein response (mtUPR) and cognate promoter elements. PloS One 2(9): e874.

Alirol E, Martinou JC (2006) Mitochondria and cancer: is there a morphological connection? Oncogene 25(34): 4706-4716.

Altieri DC (2011) Mitochondrial compartmentalized protein folding and tumor cell survival. Oncotarget 2(4): 347-351.

Altieri DC (2013) Hsp90 regulation of mitochondrial protein folding: from organelle integrity to cellular homeostasis. Cell Mol Life Sci 70(14): 2463-2472.

Bonnet S, Archer SL, Allalunis-Turner J, Haromy A, Beaulieu C, Thompson R, Lee CT, Lopaschuk GD, Puttagunta L, Bonnet S, Harry G, Hashimoto K, Porter CJ, Andrade MA, Thebaud B, Michelakis ED (2007) A mitochondria- $\mathrm{K}+$ channel axis is suppressed in cancer and its normalization promotes apoptosis and inhibits cancer growth. Cancer Cell 111: $37-51$.

Cao W, Yacoub S, Shiverick KT, Namiki K, Sakai Y, Porvasnik S, Urbanek C, Rosser CJ (2008) Dichloroacetate (DCA) sensitizes both wild-type and over expressing Bcl-2 prostate cancer cells in vitro to radiation. Prostate 68(11): 1223-1231.

Chatterjee A, Mambo E, Sidransky D (2006) Mitochondrial DNA mutations in human cancer. Oncogene 25(34): 4663-4674.

Chen G, Wang F, Trachootham D, Huang P (2010) Preferential killing of cancer cells with mitochondrial dysfunction by natural compounds. Mitochondrion 10(6): 614-625.

Chornokur G, Dalton K, Borysova ME, Kumar NB (2011) Disparities at presentation, diagnosis, treatment, and survival in African American men, affected by prostate cancer. Prostate 71(9): 985-997.

Collins AT, Berry PA, Hyde C, Stower MJ, Maitland NJ (2005) Prospective identification of tumorigenic prostate cancer stem cells. Cancer Res 65(23): 10946-10951.

Coulonval K, Bockstaele L, Paternot S, Roger PP (2003) Phosphorylations of cyclin-dependent kinase 2 revisited using two-dimensional gel electrophoresis. J Biol Chem 278(52): 52052-52060.

Dey R, Moraes CT (2000) Lack of oxidative phosphorylation and low mitochondrial membrane potential decrease susceptibility to apoptosis and do not modulate the protective effect of $\mathrm{Bcl}-\mathrm{x}(\mathrm{L})$ in osteosarcoma cells. J Biol Chem 275(10): 7087-7094.

Evan GI, Brown L, Whyte M, Harrington E (1995) Apoptosis and the cell cycle. Curr Opin Cell Biol 76: 825-834.

Fantin VR, St-Pierre J, Leder P (2006) Attenuation of LDH-A expression uncovers a link between glycolysis, mitochondrial physiology, and tumor maintenance. Cancer Cell 96: 425-434.

Fischer U, Schulze-Osthoff K (2005) New approaches and therapeutics targeting apoptosis in disease. Pharmacol Rev 57(2): 187-215.

Godley PA, Schenck AP, Amamoo MA, Schoenbach VJ, Peacock S, Manning M, Symons M, Talcott JA (2003) Racial differences in mortality among Medicare recipients after treatment for localized prostate cancer. J Natl Cancer Inst 95(22): 1702-1710.

Green DR, Reed JC (1998) Mitochondria and apoptosis. Science 281(5381): 1309-1312.

Grossfeld GD, Latini DM, Downs T, Lubeck DP, Mehta SS, Carroll PR (2002) Is ethnicity an independent predictor of prostate cancer recurrence after radical prostatectomy? J Urol 168(6): 2510-2515.

Hayn MH, Orom H, Shavers VL, Sanda MG, Glasgow M, Mohler JL, Underwood 3rd W (2011) Racial/ethnic differences in receipt of pelvic 
lymph node dissection among men with localized/regional prostate cancer. Cancer 117(20): 4651-4658.

Haynes CM, Ron D (2010) The mitochondrial UPR - protecting organelle protein homeostasis. J Cell Sci 123(Pt 22): 3849-3855.

Haynes CM, Yang Y, Blais SP, Neubert TA, Ron D (2010) The matrix peptide exporter HAF-1 signals a mitochondrial UPR by activating the transcription factor ZC376.7 in C. elegans. Mol Cell 374: 529-540.

Huang Q, Li F, Liu X, Li W, Shi W, Liu FF, O’Sullivan B, He Z, Peng Y, Tan AC, Zhou L, Shen J, Han G, Wang XJ, Thorburn J, Thorburn A, Jimeno A, Raben D, Bedford JS, Li CY (2011) Caspase 3-mediated stimulation of tumor cell repopulation during cancer radiotherapy. Nat Med 17(7): 860-866.

Indran IR, Tufo G, Pervaiz S, Brenner C (2011) Recent advances in apoptosis, mitochondria and drug resistance in cancer cells. Biochim Biophys Acta 1807(6): 735-745.

Koochekpour S, Maresh GA, Katner A, Parker-Johnson K, Lee TJ, Hebert FE, Kao YS, Skinner J, Rayford W (2004) Establishment and characterization of a primary androgen-responsive African-American prostate cancer cell line, E006AA. Prostate 60(2): 141-152.

Koochekpour S, Marlowe T, Singh KK, Attwood K, Chandra D (2013) Reduced mitochondrial DNA content associates with poor prognosis of prostate cancer in African American men. PloS One 8(9): e74688.

Koochekpour S, Willard SS, Shourideh M, Ali S, Liu C, Azabdaftari G, Saleem M, Attwood K (2014) Establishment and characterization of a highly tumorigenic african american prostate cancer cell line, E006AA-hT. Int J Biol Sci 10(8): 834-845.

Latini DM, Elkin EP, Cooperberg MR, Sadetsky N, Duchane J, Carroll PR (2006) Differences in clinical characteristics and disease-free survival for Latino, African American, and non-Latino white men with localized prostate cancer: data from CaPSURE. Cancer 106(4): 789-795.

Majmundar AJ, Wong WJ, Simon MC (2010) Hypoxia-inducible factors and the response to hypoxic stress. Mol Cell 40(2): 294-309.

McIntosh H (1997) Why do African-American men suffer more prostate cancer? J Natl Cancer Inst 89(3): 188-189.

Michelakis ED, Webster L, Mackey JR (2008) Dichloroacetate (DCA) as a potential metabolic-targeting therapy for cancer. Br J Cancer 99(7): 989-994.

Pathak RK, Marrache S, Harn DA, Dhar S (2014) Mito-DCA: a mitochondria targeted molecular scaffold for efficacious delivery of metabolic modulator dichloroacetate. ACS Chem Biol 95: 1178-1187.

Pecqueur C, Oliver L, Oizel K, Lalier L, Vallette FM (2013) Targeting metabolism to induce cell death in cancer cells and cancer stem cells. Int J Cell Biol 2013: 805975.

Pelicano H, Xu RH, Du M, Feng L, Sasaki R, Carew JS, Hu Y, Ramdas L, Hu L, Keating MJ, Zhang W, Plunkett W, Huang P (2006) Mitochondrial respiration defects in cancer cells cause activation of Akt survival pathway through a redox-mediated mechanism. J Cell Biol 1756: 913-923.

Pellegrino MW, Nargund AM, Haynes CM (2013) Signaling the mitochondrial unfolded protein response. Biochim Biophys Acta 1833(2): $410-416$.

Ponnala S, Chetty C, Veeravalli KK, Dinh DH, Klopfenstein JD, Rao JS (2012) Metabolic remodeling precedes mitochondrial outer membrane permeabilization in human glioma xenograft cells. Int J Oncol 40(2): 509-518.

Powell IJ, Banerjee M, Novallo M, Sakr W, Grignon D, Wood DP, Pontes JE (2000) Prostate cancer biochemical recurrence stage for stage is more frequent among African-American than white men with locally advanced but not organ-confined disease. Urology 55(2): 246-251.

Powell IJ, Heilbrun LK, Sakr W, Grignon D, Montie J, Novallo M, Smith D, Pontes JE (1997) The predictive value of race as a clinical prognostic factor among patients with clinically localized prostate cancer: a multivariate analysis of positive surgical margins. Urology 49(5): 726-731.

Pucci B, Kasten M, Giordano A (2000) Cell cycle and apoptosis. Neoplasia 2(4): 291-299.

Schieber M, Chandel NS (2014) ROS function in redox signaling and oxidative stress. Curr Biol 24(10): R453-R462.

Sebastian B, Kakizuka A, Hunter T (1993) Cdc25M2 activation of cyclindependent kinases by dephosphorylation of threonine-14 and tyrosine-15. Proc Natl Acad Sci USA 90(8): 3521-3524.

Seliger C, Leukel P, Moeckel S, Jachnik B, Lottaz C, Kreutz M, Brawanski A, Proescholdt M, Bogdahn U, Bosserhoff AK, Vollmann-Zwerenz A, Hau P (2013) Lactate-modulated induction of THBS-1 activates transforming growth factor (TGF)-beta2 and migration of glioma cells in vitro. PloS One 8(11): e78935.

Semenas J, Allegrucci C, Boorjian SA, Mongan NP, Persson JL (2012) Overcoming drug resistance and treating advanced prostate cancer. Curr Drug Targets 13(10): 1308-1323.

Simon HU, Haj-Yehia A, Levi-Schaffer F (2000) Role of reactive oxygen species (ROS) in apoptosis induction. Apoptosis 5(5): 415-418.

Srivastava P, Yadav N, Lella R, Schneider A, Jones A, Marlowe T, Lovett G, O'Loughlin K, Minderman H, Gogada R, Chandra D (2012) Neem oil limonoids induces p53-independent apoptosis and autophagy. Carcinogenesis 33(11): 2199-2207.

Tait SW, Ichim G, Green DR (2014) Die another way-non-apoptotic mechanisms of cell death. J Cell Sci 127(Pt 10): 2135-2144.

Underwood W, De Monner S, Ubel P, Fagerlin A, Sanda MG, Wei JT (2004) Racial/ethnic disparities in the treatment of localized/regional prostate cancer. J Urol 171(4): 1504-1507.

Warburg O (1956) On respiratory impairment in cancer cells. Science 124(3215): 269-270.

Yadav N, Kumar S, Kumar R, Srivastava P, Sun L, Rapali P, Marlowe T, Schneider A, Inigo JR, O'Malley J, Londonkar R, Gogada R, Chaudhary AK, Yadava N, Chandra D (2016) Mechanism of neem limonoids-induced cell death in cancer: role of oxidative phosphorylation. Free Radic Biol Med 90: 261-271.

Yadav N, Kumar S, Marlowe T, Chaudhary AK, Kumar R, Wang J, O'Malley J, Boland PM, Jayanthi S, Kumar TK, Yadava N, Chandra D (2015) Oxidative phosphorylation-dependent regulation of cancer cell apoptosis in response to anticancer agents. Cell Death Dis 6: e1969.

Yadav N, Pliss A, Kuzmin A, Rapali P, Sun L, Prasad P, Chandra D (2014) Transformations of the macromolecular landscape at mitochondria during DNA-damage-induced apoptotic cell death. Cell Death Dis 5: e1453.

Yu M (2012) Somatic mitochondrial DNA mutations in human cancers. Adv Clin Chem 57: 99-138.

Yu M, Zhou Y, Shi Y, Ning L, Yang Y, Wei X, Zhang N, Hao X, Niu R (2007) Reduced mitochondrial DNA copy number is correlated with tumor progression and prognosis in Chinese breast cancer patients. IUBMB Life 597: 450-457.

Zhao Q, Wang J, Levichkin, Stasinopoulos S, Ryan MT, Hoogenraad NJ (2002) A mitochondrial specific stress response in mammalian cells. EMBO J 21(17): 4411-4419.

Zhao Y, Butler EB, Tan M (2013) Targeting cellular metabolism to improve cancer therapeutics. Cell Death Dis 4: e532.

This work is published under the standard license to publish agreement. After 12 months the work will become freely available and the license terms will switch to a Creative Commons AttributionNonCommercial-Share Alike 4.0 Unported License.

Supplementary Information accompanies this paper on British Journal of Cancer website (http://www.nature.com/bjc). 